\title{
Single-breath method for assessing the viscoelastic properties of the respiratory system
}

\author{
V. Antonaglia*, A. Grop*, P. Demanins*, F. Beltrame*, U. Lucangelo*, \\ A. Peratoner*, L. De Simoni*, A. Gullo*, J. Milic-Emili+
}

Single-breath method for assessing the viscoelastic properties of the respiratory system. $V$. Antonaglia, A. Grop, P. Demanins, F. Beltrame, U. Lucangelo, A. Peratoner, L. De Simoni, A. Gullo, J. Milic-Emili. @ERS Journals Ltd 1998.

ABSTRACT: In order to explain the time dependency of resistance and elastance of the respiratory system, a linear viscoelastic model (Maxwell body) has been proposed.

In this model the maximal viscoelastic pressure $\left(P_{\text {visc, }}\right.$ max $)$ developed within the tissues of the lung and chest wall at the end of a constant-flow $\left(V^{\prime}\right)$ inflation of a given time ( $t \mathrm{I})$ is given by: $P$ visc,max $=R 2 V^{\prime}\left(1-\mathrm{e}^{-t / / \tau 2}\right)$, where $R 2$ and $\tau 2$ are, respectively, the resistance and time constant of the Maxwell body. After rapid airway occlusion at $t \mathrm{I}$, tracheal pressure $(P \operatorname{tr})$ decays according to the following function: $P \operatorname{tr}(t)=P \operatorname{visc}(t)+$

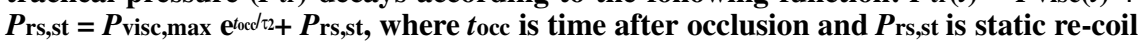
pressure of the respiratory system. By fitting $P$ tr after occlusion to this equation, $\tau_{2}$ and $P$ visc,max are obtained. Using these values, together with the $V^{\prime}$ and $t$ pertaining to the constant-flow inflation preceding the occlusion, $R 2$ can be calculated from the former equation. Thus, from a single breath, the constants $\tau_{2}, R_{2}$ and $E_{2}\left(R_{2} / \tau_{2}\right)$ can be obtained.

This method was used in 10 normal anaesthetized, paralysed, mechanically ventilated subjects and six patients with acute lung injury.

The results were reproducible in repeated tests and similar to those obtained from the same subjects and patients with the time-consuming isoflow, multiple-breath method described previously.

Eur Respir J 1998; 12: 1191-1196.
*Dept of Anaesthesia and Intensive Care, Laboratory of Respiratory Biomechanics, University of Trieste, Trieste, Italy. ${ }^{+}$Meakins-Christie Laboratories, Montreal Chest Institute Research Centre, McGill University, Montreal, Quebec, Canada.

Correspondence: V. Antonaglia

Laboratorio di Mechanica Respiratoria

Istituto di Anestesia e Rianimazione

Ospedale di Cattinara

Strada di Fiume

I-34139 Trieste

Italy

Fax: 3940912278

Keywords: Interruptor resistance static elastance

time dependency of elastance and resistance of respiratory system

Received: April 21997

Accepted after revision June 301998
In 1955, Mount [1] proposed a linear viscoelastic model in order to explain the time dependency of the resistance and elastance observed in normal rat lungs. In this model, the viscoelastic properties can be characterized by two parameters, the theoretical maximal viscoelastic resistance $(R 2)$ and elastance $\left(E_{2}\right)$. A third useful variable, the time constant $(\tau 2)$ can also be obtained as $R 2 / E 2$ [2]. Using the technique of rapid airway occlusion (RAO) during constant-flow inflation, it has been possible to determine the values of these viscoelastic constants for the lung, chest wall and total respiratory system in normal mechanically ventilated humans [3-5] and experimental animals [2, 6] based on either one of the following functions:

$$
\begin{gathered}
P \operatorname{visc}(t)=R 2 V^{\prime}\left(1-\mathrm{e}^{-t / \tau_{2}}\right) \\
R \operatorname{visc}(t)=P \operatorname{visc}(t) / V^{\prime}=R 2\left(1-\mathrm{e}^{-t / \tau_{2}}\right)
\end{gathered}
$$

where $P$ visc is viscoelastic pressure within the lung and chest wall and $P \operatorname{visc}(t)$ in Equation 1 represents the viscoelastic pressure dissipation within the lung, chest wall or both during constant-flow $\left(V^{\prime}\right)$ inflation started from the relaxed volume of the respiratory system, and $t$ is any given time during lung inflation. Equation 2 , where $R$ visc is viscoelastic resistance, is obtained by dividing both sides of Equation 1 by $V^{\prime}$ [3]. This analysis, however, is time consuming and technically complex because it requires either a series of isovolume inflations with different inspiratory flows, or multiple isoflow inflations of different volumes $[3,6]$. As a result, the above analysis has been used only in a limited number of studies on normal subjects [3-5] and patients [7-9].

In the present investigation, a single-breath method to assess the viscoelastic constants of the respiratory system is described and results obtained in normal anaesthetized paralysed subjects and in patients with acute lung injury (ALI) are provided. These data are compared with those obtained on the same subjects and patients using the method of multiple isoflow inflations of different volumes.

\section{Theory}

Figure 1 shows a representative record of tracheal pressure $(P$ tr $)$ obtained in a normal anaesthetized paralysed subject during constant-flow inflation with RAO performed at an inspiratory (inflation) time ( $t \mathrm{I})$ of $0.9 \mathrm{~s}$. End-inspiratory airway occlusion is characterized by a rapid initial drop in $P \operatorname{tr}(P \operatorname{tr}, \max -P 1$ where $P$ tr,max is maximal $P$ tr and $P 1$ is the pressure that $P$ tr,max falls to) followed by a slow decay to an apparent plateau pressure. The latter reflects the static end-inspiratory elastic recoil pressure of the respiratory system ( $P$ rs, st) whilst $P$ tr,max $-P 1$ represents the interruptor pressure, which mostly reflects flow-dependent pressure dissipations within the airways, although there is also a 


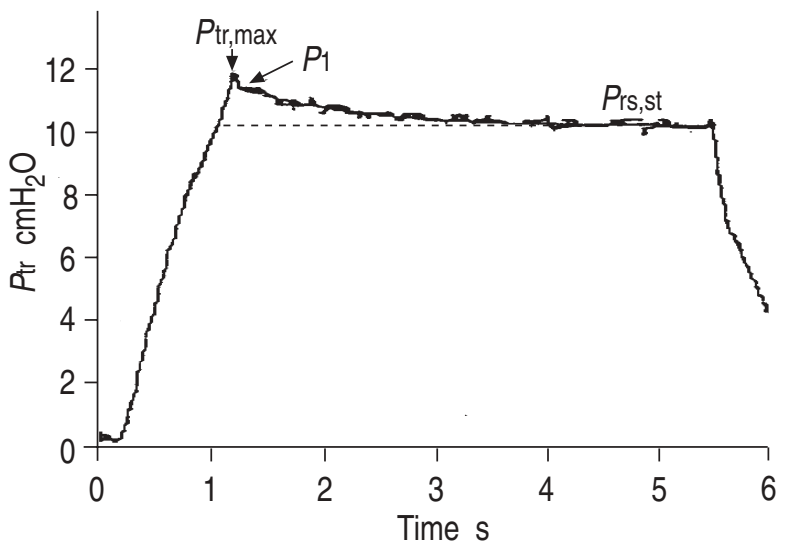

Fig. 1. - Time course of tracheal pressure $(P$ tr $)$ during constant-flow inflation and end-inspiratory airway occlusion. After end-inspiratory airway occlusion, there is an immediate drop in pressure from maximal $P \operatorname{tr}(P$ tr,max $)$ to $P 1$ followed by a slow decay to a plateau value that represents the static elastic recoil pressure of the respiratory system $\left(P_{\text {rs } s \mathrm{st}}\right)$. - : curve fitted according to Equation 5; - - - : constant $P_{\text {rs,st }}$ in Equation 5

small component due to the Newtonian resistance of the chest wall $[10,11]$. By contrast, the difference between $P 1$ and $P$ rs,st reflects $P$ visc. At the time of occlusion (i.e. $t \mathrm{I}$ ), $P$ visc is maximal and henceforth will be labelled $P$ visc,max. From Equation 1, $P$ visc,max is given by

$$
P \text { visc, } \max =R 2 V^{\prime}\left(1-\mathrm{e}^{-t / / \tau_{2}}\right)
$$

According to the viscoelastic model of Mount [1], Pvisc during the end-inspiratory occlusion, should decay according to the following function:

$$
P \text { visc }(t)=P \text { visc, max e-tocc } / 2
$$

where tocc is time after RAO. The time course of $P$ tr during the end-inspiratory occlusion is obtained by adding Prs,st to both sides of Equation 4:

$$
P \operatorname{tr}(t)=P_{\text {visc }}(t)+P_{\text {rs }, \text { st }}=P_{\text {visc }, \text { max e }}-t_{\text {toc }} \tau_{2}+P \text { rs, st }
$$

where, at $t=0, P$ tr $=P_{\text {visc }, \max }+P_{\text {rs }, \text { st }}=P_{1}$ (fig. 1 ).

By fitting the experimental time course of the decay in $P$ tr during end-inspiratory occlusion to Equation 5, the values of $P_{\text {visc,max, }} \tau 2$ and $P$ rs,st can be derived. Using the values of $P$ visc,max and $\tau 2$, together with those of $V^{\prime}$ and $t \mathrm{I}$ pertaining to the corresponding constant-flow lung inflation, the value of $R 2$ can be computed from Equation 3 . Next, $E 2$ is obtained by $E 2=R 2 / \tau 2$. Thus, during a single constant-flow inflation followed by an end-inspiratory pause with occluded airway (single-breath method), the viscoelastic constants of the respiratory system can be obtained.

\section{Materials and methods}

Ten subjects (seven males) undergoing general anaesthesia (premedication: diazepam, $7.5 \mathrm{mg}$ per os; anaesthesia: propofol, $2 \mathrm{mg} \cdot \mathrm{kg}^{-1}$ i.v.; muscle paralysis: succinylcholine, $1 \mathrm{mg} \cdot \mathrm{kg}^{-1} i . v$; maintenance: continuous infusion of propofol, $8-12 \mathrm{mg} \cdot \mathrm{kg}^{-1} \cdot \mathrm{h}^{-1}$, and vecuronium, $0.15 \mathrm{mg} \cdot \mathrm{kg}^{-1} \cdot \mathrm{h}^{-1}$ ) for minor lower abdominal or limb surgery were studied before skin incision. None had a history or clinical evi- dence of cardiopulmonary disease. Their mean ( $\pm \mathrm{SD})$ age, weight and height were $29 \pm 8 \mathrm{yrs}, 71 \pm 13 \mathrm{~kg}$ and $175 \pm 8 \mathrm{~cm}$, respectively. In all subjects the vital capacity and forced expiratory volume in one second (FEV1) were within $\pm 10 \%$ of the predicted values [12].

Six patients with ALI (arterial oxygen tension $\left(\mathrm{Pa}_{\mathrm{a}} \mathrm{O}_{2}\right) /$ inspiratory oxygen fraction $\left(F \mathrm{I}_{2} \mathrm{O}_{2}\right)<300 \mathrm{mmHg}$ and bilateral infiltrates on the chest radiograph) [13], who were admitted to the intensive care unit, were also studied. In all of them the measurements were performed after haemodynamic stabilization had been achieved for 1 day. The patients were sedated (propofol, $4 \mathrm{mg} \cdot \mathrm{kg}^{-1} \cdot \mathrm{h}^{-1}$ ) and paralysed (vecuronium $0.15 \mathrm{mg} \cdot \mathrm{kg}^{-1} \cdot \mathrm{h}^{-1}$ ). The anthropometric characteristics of the ALI patients are provided in table 1. None had a history or clinical evidence of either chronic lung disease, cardiogenic pulmonary oedema or active cardiac disease. The patients were studied at zero end-expiratory airway pressure (ZEEP). All subjects, in supine position, were intubated with a Rush cuffed endotracheal tube (7.5-8.0 $\mathrm{mm}$ i.d.) and ventilated with constant-inflation, flow-controlled ventilation by means of a Servo Ventilator 900C (Siemens-Elema AB, Solna, Sweden). RAOs were performed using a solenoid valve (Airmatic SV; Airmatic-Allied, Wilmington, OH, USA) placed next to the oral end of the endotracheal tube. The solenoid valve has a closing time of $11 \mathrm{~ms}$ (as measured at the Electronics Laboratory, Dept of Energetics, Faculty of Engineering, Trieste, Italy, with an accelerometer (Bruel \& Kjær 4332; Bruel \& Kjær Italiana, Milan, Italy) and a current probe (AC-DC Fluke Y8100; Fluke Corporation, Everett, WA, USA) connected to a rapid recorder (Hioki 8830; Hioki E.E. Corporation, Nagano, Japan)). Flow was measured with a heated Jäger Baby pneumotachograph (Würzburg, Germany) with a $\pm 3 \mathrm{~L} \cdot \mathrm{s}^{-1}$ linearity range. The pneumotachograph was inserted between the endotracheal tube and the solenoid valve, and was connected to a Validyne MP-45 pressure transducer $\left( \pm 2 \mathrm{cmH}_{2} \mathrm{O}\right.$, Northridge, CA, USA) and to a carrier amplifier (13-4615-35; Gould, Cleveland, OH, USA). Tracheal pressure was measured, via a polyethylene catheter protruding $2-3 \mathrm{~cm}$ beyond the tracheal end of the endotracheal tube with a piezoresistive differential pressure transducer (Microswitch 142PC05D; Honeywell, Scarborough, Ontario, Canada). The tracheal catheter $(1.5 \mathrm{~mm}$ i.d.) had six side holes at its distal end and an occluded tip. The system used to measure $P$ tr had no appreciable phase shift and its response was flat up to $20 \mathrm{~Hz}$. The overall dead space of the measuring equipment (excluding the endotracheal tube) was $35 \mathrm{~mL}$. The

Table 1. - Characteristics and diagnosis of patients with acute lung injury

\begin{tabular}{ccccclc}
\hline $\begin{array}{l}\text { Patient } \\
\text { No. }\end{array}$ & Sex & $\begin{array}{c}\text { Height } \\
\mathrm{cm}\end{array}$ & $\begin{array}{c}\text { Weight } \\
\mathrm{kg}\end{array}$ & $\begin{array}{c}\text { Age } \\
\text { yrs }\end{array}$ & Diagnosis & $\begin{array}{c}\mathrm{P}_{\mathrm{a}, \mathrm{O}_{2} /} \\
\mathrm{F}_{\mathrm{I}} \mathrm{O}_{2} \\
\mathrm{mmHg}\end{array}$ \\
\hline 1 & $\mathrm{M}$ & 172 & 81 & 37 & Sepsis & 145 \\
2 & $\mathrm{M}$ & 196 & 92 & 35 & Pancreatitis & 135 \\
3 & $\mathrm{~F}$ & 162 & 69 & 66 & Sepsis & 100 \\
4 & $\mathrm{M}$ & 164 & 75 & 71 & $\begin{array}{l}\text { Multiple } \\
\text { injury }\end{array}$ & 125 \\
& & & & & \\
5 & $\mathrm{~F}$ & 166 & 61 & 59 & Sepsis & 210 \\
6 & $\mathrm{M}$ & 168 & 73 & 43 & Burns & 160
\end{tabular}

M: male; F: female; $\mathrm{Pa}_{\mathrm{a}, \mathrm{O}_{2}}$ : arterial oxygen tension; $\mathrm{FI}_{\mathrm{I}} \mathrm{O}_{2}$ : inspiratory oxygen fraction. $(1 \mathrm{mmHg}=0.133 \mathrm{kPa}$.) 
resistance offered by this equipment was $8 \mathrm{cmH}_{2} \mathrm{O} \cdot \mathrm{L}^{-1} \cdot \mathrm{s}^{-1}$ at a $V^{\prime}$ of $1 \mathrm{~L} \cdot \mathrm{s}^{-1}$. Flow and $P \operatorname{tr}$ signals were fed through a 12-bit analogue-to-digital converter (Data Translation DT2801A; Data Translation, Marlboro, MD, USA) into an IBM-compatible computer. Sampling frequency was established at $200 \mathrm{~Hz}$. Volume was obtained by numerical integration of the flow signal. All data were analysed using ANADAT data analysis software (RHT-InfoData, Montreal, Quebec, Canada). Great care was taken to avoid leaks around the tracheal cuff and in the equipment. In all patients, the electrocardiogram and arterial blood pressure were monitored continuously, along with peripheral oxygen saturation and end-tidal carbon dioxide tension (Ohmeda 5250 RGM; Louisville, CO, USA). An anaesthetist who was not involved in the experiment was present to provide patient care.

\section{Experimental procedure and data analysis: baseline con- ditions}

Normal subjects were ventilated on ZEEP $\left(F \mathrm{I}, \mathrm{O}_{2}=0.4\right)$ with a $V^{\prime}$ of $0.50 \pm 0.01 \mathrm{~L} \cdot \mathrm{s}^{-1}$, a $t \mathrm{I}$ of $0.98 \pm 0.08 \mathrm{~s}$ and a respiratory frequency $(f \mathrm{R})$ of $15-16$ breaths $\cdot \mathrm{min}^{-1}$, except for subject No. 9. This patient weighed $100 \mathrm{~kg}$ and had a body weight that was $24.6 \mathrm{~kg}(33 \%)$ above the desirable weight predicted on the basis of sex, age and height (body mass index of $29.8 \mathrm{~kg} \cdot \mathrm{m}^{-2}$ ) [14]. In this patient, $t \mathrm{I}$ was set at $1.38 \mathrm{~s}$ and $f_{\mathrm{R}}$ at 11 breaths $\cdot \mathrm{min}^{-1}$. With these settings, there was normocapnia in all patients and intrinsic positive endexpiratory pressure (PEEPi) was absent, as indicated by the fact that each inflation was preceded by a period of zero flow (end-expiratory pause) and that during end-expiratory airway occlusions $P$ tr was zero. The baseline tidal volume $(V \mathrm{~T})$ amounted to $6.6 \pm 0.6 \mathrm{~mL} \cdot \mathrm{kg}^{-1}$. During the experiments, the ALI group was ventilated on $\operatorname{ZEEP}\left(F \mathrm{I}, \mathrm{O}_{2}=0.5\right)$ with a $V^{\prime}$ of $0.71 \pm 0.15 \mathrm{~L} \cdot \mathrm{s}^{-1}$, a $t \mathrm{I}$ of $0.92 \pm 0.24 \mathrm{~s}$ and an $f \mathrm{R}$ of $16-18$ breaths $\mathrm{min}^{-1}$. The mean value $( \pm \mathrm{SD})$ of PEEPi was $3.0 \pm 2.1 \mathrm{cmH}_{2} \mathrm{O}$.

\section{Single-breath method}

End-tidal inspiratory occlusions, which lasted for $4 \mathrm{~s}$, were obtained with the solenoid valve triggered by the Servo Ventilator. The volume loss due to the continuous gas exchange had a negligible impact on $P$ tr. Data collection started during an end-expiratory occlusion for assessment of PEEPi. After an end-expiratory occlusion, five recovery breaths at baseline ventilatory settings ensued; they were followed by an end-inspiratory occlusion. All measurements were repeated three times under the same experimental conditions. Between each test $V^{\prime}, V_{\mathrm{T}}$ and $P$ tr were allowed to return to baseline values.

As shown in figure 1, the end-inspiratory occlusions were followed by an initial rapid drop of $P$ tr to $P 1$ and by a subsequent gradual decrease to an apparent plateau reflecting $P_{\text {rs,st. }}$ The values of $P_{\text {visc,max }}, P_{\text {rs st }}$ and $\tau 2$ were obtained by computer fitting of the experimental data of $P$ tr obtained during end-inspiratory occlusion to Equation 5. In this analysis, curve fitting started about $25 \mathrm{~ms}$ after occlusion to avoid the initial post-occlusion oscillations in $P \operatorname{tr}[15]$ and was carried out throughout the remainder of the $4 \mathrm{~s}$. $P 1$ was obtained by back extrapolation of these exponential functions [15], whilst $P$ rs,st was taken as $P$ tr 4 s after the onset of occlusion.
In this analysis, the onset of the occluded inspiration corresponds to the end of the preceding constant $V^{\prime}$ inflation obtained with a given $t \mathrm{I}$. Accordingly, the difference $P 1-P$ rs,st should correspond to the value of the $P$ visc at $t \mathrm{I}$ $(P$ visc,max $)$. Using this value and the corresponding $\tau 2$, together with the experimental values of $V^{\prime}$ and $t \mathrm{I}, R 2$ could be computed according to Equation 3 . Since $E_{2}=R 2 / \tau_{2}$, the value of $E 2$ could also be derived. From the values of $P$ tr,max, $P 1, P$ visc, max and $P$ rs,st the following standard respiratory mechanics variables were computed [4]: 1) interruptor resistance $\left.\left(R_{\mathrm{int}}=\left(P_{\mathrm{tr}, \max }-P_{1}\right) / V^{\prime}\right) ; 2\right) R_{\mathrm{visc}}=P_{\mathrm{visc}}, \max /$ $V^{\prime}$; and 3) static and dynamic elastances of the respiratory $\operatorname{system}\left(E_{\mathrm{rs}, \mathrm{st}}=P_{\mathrm{rs}, \mathrm{st}} / V \mathrm{~T}\right.$ and $\left.E_{\mathrm{rs}, \mathrm{dyn}}=P 1 / V \mathrm{~T}\right)$.

\section{Multiple-breath method}

The isoflow occlusion method was used, as previously described in detail [3, 4]. Under the same baseline conditions, four-second end-inspiratory occlusions were performed at four or five different inflation volumes by intermittently changing $t \mathrm{I}$ while keeping the basal inflation $V^{\prime}$ constant. The corresponding occluded inflation volumes ranged from $0.3-1.25 \mathrm{~L}$. These tests were repeated three times. At each occlusion volume, the values of $R$ visc was obtained and, together with the corresponding values of $V^{\prime}$ and $t$, were fitted to Equation 2 to obtain $R 2$ and $\tau 2$. The investigation was approved by the local Ethics Committee and informed consent was obtained from each individual or their next of kin.

\section{Statistical analysis}

Regression analysis was performed using the least squares method. The paired t-test was used to compare the data of the first single-breath test with the corresponding average values obtained as the means of three repeated single-breath tests. The unpaired t-test was used to compare the present data with those of D'Angelo et al. [3]. Comparison between the results provided by single and multiplebreath methods was performed by means of the limits of agreement [16], as modified for small sample sizes [17]. The significance level was established at $\mathrm{p}<0.05$.

\section{Results}

Table 2 depicts the values of $R$ int of the respiratory system ( $R$ rs,int), $R$ visc, $E_{\mathrm{rs}, \text { st }}$ and $E_{\mathrm{rs}}$,dyn, obtained with the first single-breath test (SB1) and the average of three repeated single-breath tests ( $\mathrm{SB} 3)$ in the normal subjects and ALI patients. There was no significant difference obtained between the $\mathrm{SB}_{1}$ and $\mathrm{SB}_{3}$ results. With $\mathrm{SB}_{3}$, the mean ( $\left.\pm \mathrm{SD}\right)$ intranormal subject and intra-ALI patient coefficients of variation of $R$ rs,int, $R$ visc, $E$ rs,st and $E$ rs,dyn were $24 \pm 12 \%$; $6 \pm 6 \% ; 2 \pm 1 \%$ and $2 \pm 2 \%$, and $31.1 \pm 19 \% ; 16.6 \pm 8.7 \% ; 7.2 \pm$ $5.6 \%$ and $5.2 \pm 4 \%$, respectively. In all subjects, the data closely fitted Equation 2, the correlation coefficients (r) being highly significant $(\mathrm{p}<0.001)$. The values of $r$ ranged $0.883-0.990$ in the normal subjects and $0.871-0.981$ in ALI patients. The values of $\tau_{2}, R 2$, and $E_{2}$ obtained with $\mathrm{SB}_{1}$ and $\mathrm{SB}_{3}$ in the normal subjects and ALI patients are given in table 3 . There was no significant difference between the $\mathrm{SB} 1$ and $\mathrm{SB} 3$ results. With $\mathrm{SB} 3$, the mean $( \pm \mathrm{SD})$ intranormal subject and intra-ALI patient coefficients of variation of $\tau 2, R 2$, and $E 2$ were $10 \pm 8 \%, 7 \pm 5 \%$ and $8 \pm 9 \%$, 
Table 2. - Respiratory mechanics variables of normal subjects $(n=10)$ and patients with acute lung injury (ALI) ( $n=6)$ obtained using the single-breath method

\begin{tabular}{|c|c|c|c|c|c|c|c|c|}
\hline & \multicolumn{4}{|c|}{ Normal subjects } & \multicolumn{4}{|c|}{ ALI patients } \\
\hline & $\begin{array}{c}\text { Ers,st } \\
\mathrm{cmH}_{2} \mathrm{O} \cdot \mathrm{L}^{-1}\end{array}$ & $\begin{array}{c}\text { Ers,dyn } \\
\mathrm{cmH}_{2} \mathrm{O} \cdot \mathrm{L}^{-1}\end{array}$ & $\begin{array}{c}\text { Rrs,int } \\
\mathrm{cmH}_{2} \mathrm{O} \cdot \mathrm{L}^{-1} \cdot \mathrm{s}^{-1}\end{array}$ & $\begin{array}{c}R \text { visc } \\
\mathrm{cmH}_{2} \mathrm{O} \cdot \mathrm{L}^{-1} \cdot \mathrm{s}^{-1}\end{array}$ & $\begin{array}{c}\text { Ers,st } \\
\mathrm{cmH}_{2} \mathrm{O} \cdot \mathrm{L}^{-1}\end{array}$ & $\begin{array}{c}\text { Ers,dyn } \\
\mathrm{cmH}_{2} \mathrm{O} \cdot \mathrm{L}^{-1}\end{array}$ & $\begin{array}{c}\text { Rrs,int } \\
\mathrm{cmH}_{2} \mathrm{O} \cdot \mathrm{L}^{-1} \cdot \mathrm{s}^{-1}\end{array}$ & $\begin{array}{c}R \text { visc } \\
\mathrm{cmH}_{2} \mathrm{O} \cdot \mathrm{L}^{-1} \cdot \mathrm{s}^{-1}\end{array}$ \\
\hline$\overline{\mathrm{SB} 1}$ & $18.8 \pm 3.4$ & $22.4 \pm 3.7$ & $1.49 \pm 0.81$ & $2.88 \pm 0.65$ & $23.3 \pm 8.4$ & $30.1 \pm 14.7$ & $4.14 \pm 2.12$ & $4.36 \pm 1.28$ \\
\hline SB3 & $18.8 \pm 3.5$ & $22.3 \pm 3.8$ & $1.56 \pm 0.86$ & $2.98 \pm 0.64$ & $22.8 \pm 8.7$ & $30.7 \pm 15.1$ & $3.91 \pm 1.52$ & $4.58 \pm 1.32$ \\
\hline
\end{tabular}

Values are presented as means \pm SD. SB1: first single-breath test; SB3: average of three single-breath tests; Ers,st: static elastance of the respiratory system; $E \mathrm{rs}$,dyn: dynamic elastance of the respiratory system; $R \mathrm{rs}$,int: interrupter resistance of the respiratory system; $R$ visc: viscoelastic resistance.

and $14.4 \pm 10 \%, 15.6 \pm 12.9 \%$ and $15.5 \pm 6.3 \%$, respectively. Table 3 also depicts the mean values of $\tau 2, R 2$, and $E 2$ obtained with the multiple breath method. The mean differences ( \pm SD) of $\tau 2, R 2$, and $E 2$ in normal subjects were $-0.09 \pm$ $0.42 \mathrm{~s},-0.19 \pm 0.66 \mathrm{cmH}_{2} \mathrm{O} \cdot \mathrm{L}^{-1}$ and $0.27 \pm 0.66 \mathrm{cmH}_{2} \mathrm{O} \cdot \mathrm{L}^{-1} \cdot \mathrm{s}^{-1}$, respectively. The mean differences $( \pm \mathrm{SD})$ of $\tau 2, R 2$, and $E 2$ in ALI patients were $-0.11 \pm 0.24 \mathrm{~s},-1.13 \pm 1.10 \mathrm{cmH}_{2} \mathrm{O} \cdot \mathrm{L}^{-1} \cdot \mathrm{s}^{-1}$, $-0.19 \pm 1.43 \mathrm{cmH}_{2} \mathrm{O} \cdot \mathrm{L}^{-1}$, respectively. No lack of agreement could be detected between the two methods for all variables in normal subjects and in ALI patients.

Figure $2 \mathrm{a}$ depicts the relationships between the average values of $R$ visc and $t$ I obtained with the multiple-breath method in the 10 normal subjects and six ALI patients, together with those predicted according to Equation 2, using the individual values of the viscoelastic constants obtained with the single-breath method (both SB1 and SB3). Figure $2 \mathrm{~b}$ depicts the corresponding changes in elastance of the respiratory system $(\Delta E \mathrm{rs})$. The latter relationship was obtained according to the following equation [4]:

$$
\Delta E \text { rs }=P_{\text {visc }, \max } / V=R 2 V^{\prime}\left(1-\mathrm{e}^{-\mathrm{t} / / \tau_{2}}\right) / V
$$

where $V$ is inflation volume. Equation 6 is obtained by dividing both sides of Equation 3 by $V$. Also shown on the right ordinate of fig. $2 \mathrm{~b}$ is the ratio $E$ rs,dyn/ $E$ rs,st in the normal subjects and in ALI patients, where Ers,dyn is the sum of $\Delta E$ rs and $E$ rs,st. In these computations, the average values of $E$ rs,st found with the single-breath method in the 10 normal subjects $\left(18.8 \mathrm{cmH}_{2} \mathrm{O} \cdot \mathrm{L}^{-1}\right)$ and in the six ALI patients $\left(22.75 \mathrm{cmH}_{2} \mathrm{O} \cdot \mathrm{L}^{-1}\right)$ were used.

\section{Discussion}

\section{Viscoelastic constants of the respiratory system}

The standard mechanics variables were obtained during single-breath RAO manoeuvres performed at baseline lung inflation volume (fig. 1) [3-5]. The present investigation shows that the viscoelastic constants of the respiratory system can also be derived from the same manoeuvre. This method is reproducible and does not require many repeated occlusion tests, as is the case for the isoflow and isovolume multiple-breath methods previously used [35]. Furthermore, this analysis is based on Equations 3 and 5, which are independent of $R \mathrm{rs}$,int and Ers,st. Accordingly, the estimates of the viscoelastic constants obtained with the single-breath method are not affected by the volume dependence of $E$ rs,st or the volume and flow dependence of $R \mathrm{rs}$,int [3]. As with the multiple-breath method, the viscoelastic constants may be obtained from measurements of pressure at the airway opening instead of $P \operatorname{tr}$ [3]. The values of the viscoelastic constants obtained with the single-breath method were not significantly different from those obtained with the isoflow multiple-breath method. Using the isoflow multiple-breath method, D'ANGELo et al. [3] determined the viscoelastic constants of the total respiratory system in 16 normal young subjects under similar experimental conditions to those of the present study. Their values of $\tau_{2}, R 2$, and $E_{2}$ amounted to $0.96 \pm 0.2 \mathrm{~s}$, $4.60 \pm 0.81 \mathrm{cmH}_{2} \mathrm{O} \cdot \mathrm{L}^{-1} \cdot \mathrm{s}^{-1}$ and $5.10 \pm 1.57 \mathrm{cmH}{ }_{2} \mathrm{O} \cdot \mathrm{L}^{-1}$, respectively, and are not significantly different from those obtained in the present study with the multiple-breath method. Using a modified multiple-breath method, Jonson et al. [18] determined the viscoelastic constants of the respiratory system in six normal, anaesthetized paralysed subjects, which also do not differ significantly from the present results.

As in normal subjects, in ALI patients the viscoelastic constants could be obtained by the single-breath method and the values were not significantly different from those obtained by the multiple breath method. In patients and animal models of lung disease, $\tau 2, R 2$, and $E 2$ represent not only viscoelasticity, but also the mechanical inhomogeneities of the lung. In this line, the values found in the present ALI patients should be regarded as encompassing viscoelasticity and/or mechanical inhomogeneities of the respiratory system. In ALI patients the values of $R 2$, and $E 2$ were significantly higher than in normal subjects while $\tau 2$ was not significantly different. This suggest that most

Table 3. - Viscoelastic time constant $\left(\tau_{2}\right)$, resistance $\left(R_{2}\right)$, and elastance $\left(E_{2}\right)$ of the respiratory system in normal subjects $(n=10)$ and in patients with acute lung injury (ALI) $(n=6)$

\begin{tabular}{|c|c|c|c|c|c|c|}
\hline & \multicolumn{3}{|c|}{ Normal subjects } & \multicolumn{3}{|c|}{ ALI patients } \\
\hline & $\begin{array}{c}\tau 2 \\
\mathrm{~s}\end{array}$ & $\begin{array}{c}R 2 \\
\mathrm{cmH}_{2} \mathrm{O} \cdot \mathrm{L}^{-1} \cdot \mathrm{s}^{-1}\end{array}$ & $\begin{array}{c}E 2 \\
\mathrm{cmH}_{2} \mathrm{O} \cdot \mathrm{L}^{-1}\end{array}$ & $\begin{array}{l}\tau 2 \\
\mathrm{~s}\end{array}$ & $\begin{array}{c}R 2 \\
\mathrm{cmH}_{2} \mathrm{O} \cdot \mathrm{L}^{-1} \cdot \mathrm{s}^{-1}\end{array}$ & $\begin{array}{c}E 2 \\
\mathrm{cmH}_{2} \mathrm{O} \cdot \mathrm{L}^{-1}\end{array}$ \\
\hline$\overline{\mathrm{SB} 1}$ & $1.13 \pm 0.17$ & $4.82 \pm 1.28$ & $4.25 \pm 0.65$ & $1.31 \pm 0.51$ & $9.79 \pm 6.57$ & $7.43 \pm 2.96$ \\
\hline SB3 & $1.17 \pm 0.19$ & $5.09 \pm 1.25$ & $4.38 \pm 0.77$ & $1.29 \pm 0.39$ & $9.20 \pm 4.27$ & $7.27 \pm 2.80$ \\
\hline MB & $1.08 \pm 0.37$ & $4.89 \pm 1.32$ & $4.66 \pm 0.83$ & $1.40 \pm 0.50$ & $10.33 \pm 4.99$ & $7.45 \pm 2.12$ \\
\hline
\end{tabular}

Values are presented as means \pm SD. SB1: first single-breath test; SB3: average of three single-breath tests; MB: multiple-breath method. 

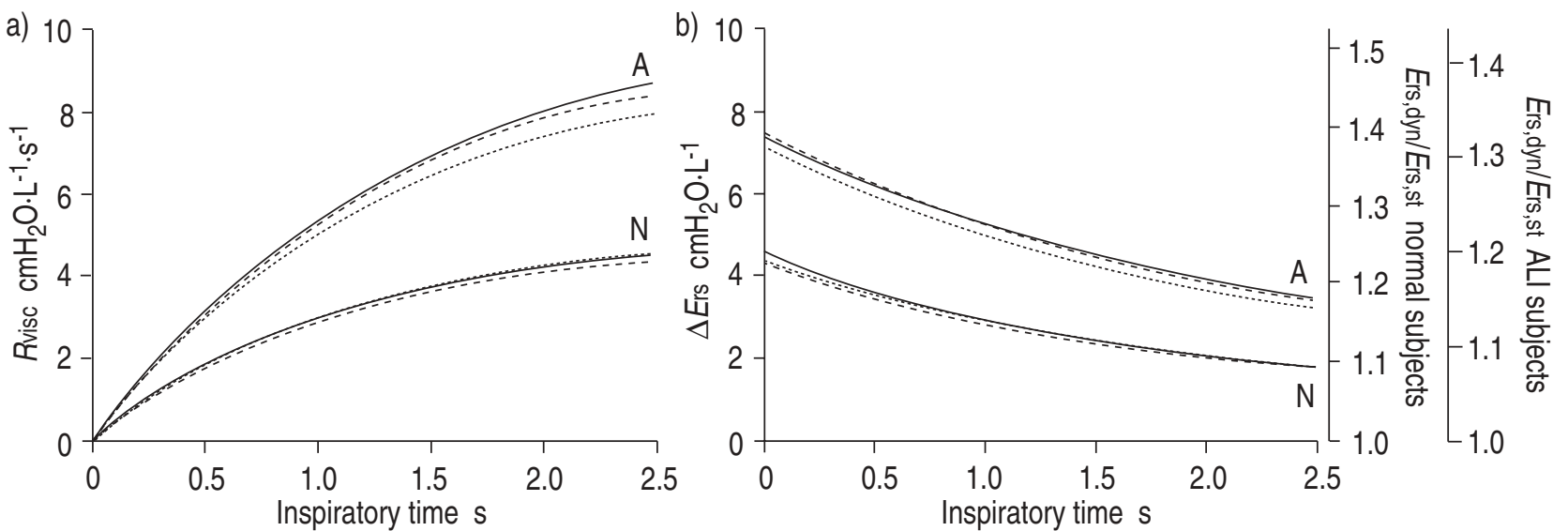

Fig. 2. - Average relationships of a) viscoelastic resistance ( $R$ visc) and b) elastance of the respiratory system ( $\Delta E$ rs) to inspiratory time in 10 normal subjects and six patients with acute lung injury (ALI) obtained using the single-breath method ( - - - : first test; .......... average of three tests) and using the multiple-breath method (_- In ALI patients, maximal viscoelastic pressure ( $P$ visc,max) includes pressure losses due to time-constant inhomogeneity within the lung. Also shown on the right ordinate of b) are the changes in dynamic elastance of the respiratory system $(E r s$, dyn $=$ elastance of

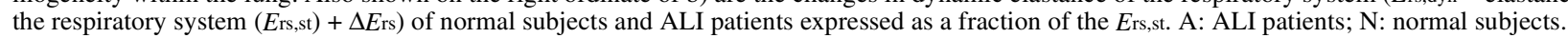

of the increase in $R 2$, and $E 2$ in ALI patients was due mainly to a reduction in lung volume. Indeed, according to the "baby lung" concept of GATTINONI et al. [19], in ALI patients the aerated parts of the lung should be normal (as reflected by the unchanged $\tau 2$ ), while the increase in $R 2$, and $E 2$ should simply reflect reduced lung volume.

This analysis, which was based on a linear viscoelastic model, should not be regarded as a complete and perfect representation of respiratory mechanics. More complex nonlinear viscoelastic [20] and viscoplastoelastic models [21] have been used to explain the volume and time dependency of energy dissipation within the respiratory system. Nevertheless, the linear viscoelastic model has been shown to provide an accurate description of the time dependency of resistance and elastance over the lung volume range used in the present study [3-5]. In fact, the present results show that the $t \mathrm{I}$ dependency of resistance and elastance of the total respiratory system can be predicted with reasonable accuracy from the values of viscoelastic constants obtained with the single-breath method, as shown in figure 2. This is especially true for the range of $t \mathrm{I}$ commonly used during mechanical ventilation (up to $2 \mathrm{~s}$ ). Thus, with the single-breath method, not only can the values of $R$ visc and Ers,dyn during baseline ventilation be obtained, but the $t$ I dependence of these variables can also be provided (fig. 2).

\section{Rrs,int and Ers,int}

In the present investigation $R$ rs,int amounted to $1.49 \pm$ $0.81 \mathrm{cmH}_{2} \mathrm{O} \cdot \mathrm{L}^{-1} \cdot \mathrm{s}^{-1}$ with $\mathrm{SB} 1$ and $1.56 \pm 0.86 \mathrm{cmH}_{2} \mathrm{O} \cdot \mathrm{L}^{-1} \cdot \mathrm{s}^{-1}$ with SB3. These values were significantly lower $(\mathrm{p}<0.02)$ than those found in 16 normal young subjects by D'AN-GELO et al. [3]. These authors, however, did not obtain $R$ rs,int directly from measurements of $P \mathrm{tr}$, as in the present study. Instead, they derived Rrs,int indirectly by correcting the drop in airway opening pressure after end-inspiratory occlusion for the resistive pressure drop due to the endotracheal tube, which was measured in vitro. This indirect method, however, is not accurate [22]. Indeed, in a subsequent study based on $P$ tr measurements in 12 normal sub- jects, D'Angelo et al. [11] found values of Rrs,int similar to those of the present study $\left(1.54 \pm 0.46 \mathrm{cmH}_{2} \mathrm{O} \cdot \mathrm{L}^{-1} \cdot \mathrm{s}^{-1}\right)$. In the present study, the mean intrasubject coefficient of variation of $R \mathrm{rs}$,int was relatively high, amounting to $24 \pm 12 \%$. This reflects the fact that in some of the subjects at inflation flow of $0.5 \mathrm{~L} \cdot \mathrm{s}^{-1}$, the values of $P \max -P 1$ were relatively low in relation to the cardiac artefacts in $P$ tr. In such instances, accurate assessment of $R$ rs,int requires ensemble averaging of several end-inspiratory occlusion records [11]. The present values of Ers,st were similar to those found in two previous studies on normal young subjects under similar experimental conditions $[4,11]$, but significantly higher than those found by D'Angelo et al. [3]. The reason for this discrepancy is not clear.

The single-breath method was also successfully applied to ALI patients who were selected according to the North American-European Consensus Conference [13]. The definition of ALI encompasses a wide range of severity of sickness, which is reflected in the marked interindividual variation in respiratory mechanics values in the ALI patients (tables 2 and 3 ).

\section{Conclusions}

The results show that with the single-breath method it is possible to derive not only the standard mechanics data but also the inflation time-dependence of the viscoelastic resistance and the dynamic elastance of the respiratory system as well as the viscoelastic constants of the respiratory system in both normal subjects and patients with acute lung injury.

\section{References}

1. Mount LE. The ventilation flow-resistance and compliance of rat lungs. $J$ Physiol Lond 1955; 127: 157-167.

2. Similovski T, Levy P, Corbeil C, et al. Viscoelastic behavior of lung and chest wall in dogs determined by flow interruption. J Appl Physiol 1989; 67: 2219-2229.

3. D'Angelo E, Calderini E, Torri G, Robatto FM, Bono D, 
Milic-Emili J. Respiratory mechanics in anesthetized paralyzed humans: effects of flow, volume, and time. $J$ Appl Physiol 1989; 67: 2556-2564.

4. D'Angelo E, Robatto FM, Calderini E, et al. Pulmonary and chest wall mechanics in anesthetized paralyzed humans. J Appl Physiol 1991; 70: 2602-2610.

5. D'Angelo E, Calderini E, Tavola M, Bono D, Milic-Emili J. Effect of PEEP on respiratory mechanics in anesthetized paralyzed humans. J Appl Physiol 1992; 73: 17361742.

6. Shardonofsky FR, Skaburskis M, Sato J, Zin WA, Milic-Emili J. Effects of volume history and vagotomy on pulmonary and chest wall mechanics in cats. J Appl Physiol 1991; 71: 498-508.

7. Eissa NT, Ranieri VM, Corbeil C, et al. Analysis of behaviour of the respiratory system in ARDS patients: effects of flow, volume and time. J Appl Physiol 1991; 70: 2719-2729.

8. Eissa NT, Ranieri VM, Corbeil C, Chasse M, Braidy J, Milic-Emili J. Effect of PEEP on the mechanics of the respiratory system in ARDS patients. J Appl Physiol 1992; 73: 1728-1735.

9. Guérin C, Coussa M-L, Eissa NT, et al. Lung and chest wall mechanics in mechanically ventilated COPD patients. J Appl Physiol 1993; 74: 1570-1580.

10. Auler JOC Jr, Zin WA, Caldeira MPR, Cardoso WV, Saldiva PHN. Pre- and postoperative inspiratory mechanics in ischemic and valvular heart disease. Chest 1987; 92: 984-990.

11. D'Angelo E, Prandi E, Tavola M, Calderini E, MilicEmili J. Chest wall interrupter resistance in anesthetized paralyzed humans. J Appl Physiol 1994; 77: 883-887.

12. Morris JF, Koski A, Jonhson LC. Spirometric standards for healthy nonsmoking adults. Am Rev Respir Dis 1971;
103: 57-67.

13. Bernard GR, Artigas A, Brigham KL, et al. The American- European Consensus Conference of ARDS: definitions, mechanisms, relevant outcomes, and clinical trial coordination. Am J Respir Crit Care Med 1994; 149: 818824.

14. Dien K, ed. Documenta Geigy, Scientific Tables, 6th Edn. Montreal, Geigy Pharmaceuticals, 1962; p. 624.

15. Bates JHT, Hunter I, Sly P, Okubo S, Filiatrault S, Milic-Emili J. The effect of valve closure time on the determination of respiratory resistance by flow interruption. Med Biol Eng Comp 1987; 25: 136-140.

16. Bland JM, Altman DG. Statistical methods for assessing agreement between two methods of clinical measurement. Lancet 1986; i: 307-310.

17. Chinn S. Repeatability and method comparison. Thorax 1991; 46: 454-456

18. Jonson B, Beydon L, Brauer K, Mansson C, Valind S, Grytzell H. Mechanics of respiratory system in healthy anesthetized humans with emphasis on viscoelastic properties. J Appl Physiol 1993; 75: 132-140.

19. Gattinoni L, Pesenti A, Avalli L, Rossi F, Bombino M. Pressure-volume curve of total respiratory system in acute respiratory failure. Am Rev Respir Dis 1987; 136: 730-736.

20. Suki B, Bates JHT. A non linear viscoelastic model of lung tissue mechanics. J Appl Physiol 1991; 71: 826-833.

21. Hildebrandt J. Pressure-volume data of cat lung interpreted by a plastoelastic linear viscoelastic model. $J$ Appl Physiol 1970; 28: 365-372.

22. Wright PE, Marini JJ, Bernard GR. In vitro versus in vivo comparison of endotracheal tube air-flow resistance. $A m$ Rev Respir Dis 1989; 140: 10-16. 